\title{
Respiratory involvement in inflammatory bowel diseases
}

\section{Interessamento respiratorio nelle malattie infiammatorie intestinali}

\author{
Nadia D'Andrea, Rossana Vigliarolo, Claudio M. Sanguinetti \\ Pulmonary and Intensive Care Unit, San Filippo Neri General Hospital, Rome, Italy
}

\begin{abstract}
Inflammatory bowel diseases (IBD) include ulcerative colitis (UC) and Crohn's disease (CD) and are due to a dysregulation of the antimicrobial defense normally provided by the intestinal mucosa. This inflammatory process may extend outside the bowel to many organs and also to the respiratory tract. The respiratory involvement in IBD may be completely asymptomatic and detected only at lung function assessment, or it may present as bronchial disease or lung parenchymal alterations. Corticosteroids, both systemic and aerosolized, are the mainstay of the therapeutical approach, while antibiotics must be also administered in the case of infectious and suppurative processes, whose sequels sometimes require surgical intervention. The relatively high incidence of bronchopulmonary complications in IBD suggests the need for a careful investigation of these patients in order to detect a possible respiratory involvement, even when they are asymptomatic.
\end{abstract}

Keywords: Crohn's disease, inflammatory bowel disease, respiratory involvement, ulcerative colitis.

\section{RIASSUNTO}

Le IBD (inflammatory bowel diseases) includono la colite ulcerosa (UC) e il morbo di Crohn (CD), causate da un'alterazione della difesa antimicrobica normalmente esercitata dalla mucosa gastroenterica. Questo processo infiammatorio può estendersi al di fuori dell'intestino in altri organi e anche all'apparato respiratorio. Il coinvolgimento respiratorio nelle IBD può essere del tutto asintomatico e rilevabile solo all'esame della funzionalità respiratoria, oppure manifestarsi con sintomi di patologia delle vie aeree o del parenchima polmonare. I corticosteroidi, sia per via sistemica che inalatoria, sono il caposaldo della terapia, mentre anche gli antibiotici debbono essere somministrati nelle forme infettive e con ampia componente suppurativa, i cui reliquati talvolta richiedono un approccio chirurgico. La relativamente elevata incidenza di complicazioni broncopolmonari nelle IBD suggerisce la necessità di un'accurata valutazione di questi pazienti per rivelare un eventuale coinvolgimento respiratorio, anche in assenza di sintomi.

Parole chiave: Coinvolgimento respiratorio, colite ulcerosa, malattie infiammatorie intestinali, morbo di Crohn.

\section{Definition and pathogenesis of IBD}

Ulcerative colitis (UC) and Crohn's disease (CD) are usually referred to with the common label of inflammatory bowel diseases (IBD) due to their similar inflammatory nature and unknown cause. However, many differences in the clinical and pathologic features of these two chronic intestinal diseases have been found. Ulcerative colitis involves the rectum and may affect part or all of colon, and the inflammation is typically restricted to the mucosa. Crohn's disease, on the other hand, is generally limited to the ileum and colon, not rarely in a patchy manner, and the inflammation is mostly transmural, with consequent stenosis and fistulae.

IBD result from an impaired barrier function of the intestinal mucosa characterized by increased permeability and defective regulation of tight junctions [1]. The failure of this barrier, determining an exposition to fecal antigens, may induce an inappropriate activation of the acquired mucosal immune system [2]. As a matter of fact, antibodies against intestinal bacteria are frequently detected in serum of patients with IBD [3] but, although many pathogens have been incriminated, none has been demonstrated to play a causative role $[4,5]$. The initial fast,

$\equiv$ Nadia D'Andrea

UOC di Pneumologia-UTIR, ACO San Filippo Neri

Via Martinotti 20, 00135 Roma, Italy

email: n.dandrea@sanfilipponeri.roma.it

Data di arrivo del testo: 16/03/2010 - Accettato per la pubblicazione: 15/04/2010

Multidisciplinary Respiratory Medicine 2010; 5(3): 173-182 
generic response to intestinal microbes is supplied by the innate immune system, while the adaptive immune system recognizes individual bacteria through antigen-specific receptors.

A number of inflammatory cells and mediators and genetic alterations involved in the pathogenesis of IBD have been identified in recent years [5]. The Th1 cytokines interleukin (IL)-12, interferon- $\gamma$, and tumor necrosis factor (TNF)- $\alpha$ are the main mediators of inflammation found in CD [6], whereas in UC an increased expression of Th2 cytokine IL-5 is often seen. Elevated levels of IL-23 and Th17 cytokines have been found in both CD and UC [7]. As to the innate immune system, genetic factors play an important role in the development of IBD, particularly in CD. In this respect, the first identified locus is located at the chromosome position $16 q 12$ $[8,9]$ and the different genes included within this locus are named NOD2. The NOD2 system encodes an intracellular sensor of peptidoglycan (a component of bacterial cell wall) and activates components of the innate immune system. The stimulation of the NOD2 leads to the production of cytokines and antimicrobial peptides, and an impaired response at this level is now recognized as the likely cause of IBD $[10,11]$. In fact, in healthy subjects NOD2, primed by microbial peptidoglycans, activates nuclear factor(NF)- $\mathrm{B}$, which in turn enhances the production of antibacterial cytokines. However, the acute stimulation of NOD2 by bacterial peptidoglycans is also modulated by inhibitory cytokines, like transforming growth factor (TGF)- $\beta$ and IL-10, which downregulate the proinflammatory cytokines, and this downregulation is impaired in subjects with IBD, who are thus exposed to a chronic intestinal inflammation. Three NOD2 polymorphisms have been seen in about 30\% of European patients, each impairing responses to peptidoglycans. Carriers of a NOD2 polymorphism are more likely than non carriers to have an ileal involvement [12]. Homozygosis for a polymorphism confers a much greater risk of CD [13]. In addition, autophagy, a mechanism aimed to clear microbes, and its gene ATG16L1, are involved in CD [14], where abnormal Paneth-cell morphology has also been found [15]. The autophagy is implicated in Tcell tolerance; thus in IBD an increased susceptibility to intestinal inflammation occurs, due to defects in T-cell tolerance $[16,17]$.

\section{Incidence of respiratory diseases (RD) in IBD and of IBD in RD}

Respiratory diseases are a possible complication of IBD, even if pulmonary alterations are often overlooked, especially when respiratory symptoms are already present before the diagnosis of IBD. The first recognition of a correlation between the diseases of the two districts is attributable to Kraft [18], who in 1976 reported a series of patients with unexplained bronchial suppuration. Since then, numerous reports have outlined the association between IBD and respiratory pathologies. The rate of extra-intestinal manifestations in patients with IBD ranges from
21 to $41 \%[19,20]$, increasing with the duration of the intestinal disease, and being greater in $\mathrm{CD}$ than in UC [21]. However, the true prevalence of lung involvement in IBD remains unknown and it seems rather variable, because in some series only few cases of respiratory complications have been found. In fact, in 624 patients [22] no respiratory complication was reported, and only 3/1400 cases of IBD were found by Rodgers et al. (0.4\%) [23]. On the other hand, it can be difficult to establish a relationship between IBD and RD in patients who are already affected with pulmonary disease at the diagnosis of IBD, or are current smokers.

Respiratory diseases occurring in IBD may consist merely in a subclinical abnormal lung function or, in contrast, they may manifest as clear interstitial lung disease [19]. An ongoing bowel inflammation is not a prerequisite for the onset of respiratory alterations, since bronchopulmonary diseases that developed after colectomy have been reported [24]. The respiratory changes can occur at any time in the history of IBD, but they generally follow it by a time interval varying from days to decades [25].

Concerning the "respiratory dysfunction in asymptomatic patients", Mohamed-Hussein et al. [26] reported that $57.6 \%$ of their patients with UC had at least one abnormal lung function test (PFT) result: restrictive dysfunction in $30.7 \%$ and obstructive in $11.5 \%$. The impairment of PFT was more pronounced and significant in patients with active UC than in controls or in patients with the inactive form. In a review including over 600 patients with UC, more than $50 \%$ of patients showed abnormal PFT results when compared to healthy controls, and the decrease in diffusion capacity of the lung for carbon monoxide ( $\mathrm{DL}_{\mathrm{CO}}$ ) was the most common defect [19]. The impairment of pulmonary function has been observed also in children. Munck et al. [27] first reported a series of 26 children with CD in acute or quiescent phase, all non-smokers and asymptomatic. Ten of them were studied before the start of therapy so as to exclude possible influence of therapy itself on the respiratory abnormalities. During the remission the value of $\mathrm{DL}_{\mathrm{CO}}$ resulted higher than during the acute phase $(p<0.0001)$ even if $50 \%$ of patients still presented an abnormal $\mathrm{DL}_{\mathrm{CO}}$. With the aim of investigating possible differences in respiratory function abnormalities between the two IBD identities, Tzanakis et al. [28] studied 132 patients (47 CD and 85 UC). An increased, though not significant, percentage of abnormal PFT results among both patient groups was observed compared to controls. A statistically significant difference was found only for the DL patients when compared to controls $(p<0.05)$, and a slightly greater, but significant, reduction of $\mathrm{DL}_{\mathrm{CO}}$ in the active compared to the inactive CD and UC. In a study of 66 IBD patients (35 CD and 31 UC), Herrlinger et al. [29] found $42 \%$ with at least one abnormal pulmonary function test compared to $3 \%$ of controls, and with no significant difference between both diseases. The forced expiratory volume in one second $\left(\mathrm{FEV}_{1}\right)$ and the inspiratory vital 
capacity (IVC) resulted significantly dependent on the disease activity, whereas the $\mathrm{DL}_{\mathrm{CO}}$ was not. None of the patients complained of pulmonary symptoms. Douglas et al. [30] and Bonnier et al. [31] found no correlation between $\mathrm{DL}_{\mathrm{CO}}$ reduction and disease activity or severity of IBD. DierkesGlobisch and Mohr [32] investigated 44 IBD patients without pulmonary symptoms, 20\% of whom showed an obstructive or restrictive ventilatory defect compared to $5 \%$ of controls ( $p<0.05 \%$ ), but with no correlation to activity and duration of bowel disease or to smoking habit.

From all these reports it seems clear that the pulmonary involvement in IBD is more frequent than believed, has no clear relationship with the activity of the intestinal disease and often is asymptomatic and detectable only at the lung function investigation. This is further supported by the finding by Wallaert et al. of a high proportion of latent lymphocytic pulmonary alveolitis in the bronchoalveolar lavage (BAL) of 18 consecutive patients with CD, all free from respiratory symptoms and showing a normal chest X-ray [33]. In fact, an abnormal percentage of alveolar lymphocytes was observed in 11 of 18 patients $(61 \%)$ with a T-lymphocyte prevalence. The same was found by Sarioglou et al. at the BAL fluid examination, where a lymphocytic alveolitis was evident in $46.6 \%$ of IBD cases [34].

A number of clinical lung diseases can be found in the course of IBD, but the true frequency of these conditions is unknown [19], although it has been shown that the incidence is higher in patients with UC than in those with CD (35). Respiratory diseases in patients affected by IBD can be classified as "airways disease": tracheobronchial stenosis, bronchiectasis, chronic bronchial suppuration, chronic bronchitis, COPD, asthma and bronchiolitis; "parenchymal disease": cryptogenic organizing pneumonia (COP), interstitial lung disease, localized interstitial fibrosis, necrotic nodule and eosinophilic pneumonitis; "pleural effusions" are uncommon as a manifestation of IBD (Table I).

According to Black et al. [36], who report 171 respiratory pathologies in 155 patients, the "large airways" are the most common site of involvement in IBD, accounting for $39 \%$ of all cases, and bronchiectasis was present in $66 \%$ of these cases. The second most frequently reported respiratory disease in IBD patients is chronic bronchitis [37], detected in a surprisingly high proportion (81\%) of nonsmoker patients [36]. This led the authors [36] to affirm that in these patients the bronchial inflammation is mainly caused by a diffusion of the bowel inflammatory condition to the bronchial tree. These results confirm the previous findings of Camus et al. [35] where 15/33 patients (45.4\%) with IBD had large airways involvement, six of them (40\%) in the form of bronchiectasis; 9 of the 15 cases were postcolectomy. Bronchiectasis was also the predominant finding in the report of Spira et al. [38] regarding 7 patients with IBD and large airways involvement, where three of them developed respiratory symptoms in 1-4 months after colectomy. Finally,
Kelly et al. [39], in a retrospective analysis of patients with IBD and respiratory manifestations, identified 10 patients with bronchiectasis, 8 of whom post colectomy. These authors also reported that bronchiectasis in IBD patients is more severe, more rapidly progressive and more responsive to steroids than in non IBD patients. Moreover, since colectomy has no effect on the respiratory involvement, they formulated the hypothesis that the discontinuation of anti-inflammatory drugs after the surgical resection of an intestinal tract is probably able to uncover or worsen the pulmonary manifestations.

The involvement of the "small airways" in IBD, considered rare in both entities, has proved more frequent than was supposed in the days before expiratory high resolution computed tomography (HRCT) of the chest was introduced. This imaging tool has allowed the detection of the small airways involvement in these patients, some of whom also with normal PFT results. In like manner, Songur et al. [40] examined with PFT and inspiratory and expiratory HRCT 36 patients with IBD (23 UC and 13 CD, only one with CD a current smoker), and 14 healthy non-smokers, free from respiratory symptoms. Nineteen (53\%) patients had HRCT abnormalities, with features suggestive of air trapping in expiratory CT scan in 12 (33\%) patients, 6 of whom were symptomatic. No significant correlation was found between HRCT abnormalities and PFT results, whereas there was a difference between the two

\section{TABLE I: RESPIRATORY ALTERATIONS IN IBD}

Respiratory function defects

- Restrictive

- Obstructive

- Hyperinflation

- BHR

- DLco abnormality

\section{Airways disease}

- Glottic or subglottic stenosis

- Tracheal stenosis

- Chronic bronchitis

- COPD

- Bronchiectasis

- Bronchiolitis

- Asthma

\section{Parenchymal disease}

- Diffuse interstitial lung disease

- COP

- Pulmonary granulomatosis

- Pulmonary vasculitis

- Necrobiotic pulmonary nodules

Drug-induced pneumonitis

Definition of abbreviations: BHR, bronchial hyperresponsiveness; COP, cryptogenic organizing pneumonia; COPD, chronic obstructive pulmonary disease; $\mathrm{DL}_{\mathrm{co}}$, diffusion capacity of the lung for carbon monoxide; IBD, inflammatory bowel diseases. 
types of IBD as to the incidence of CT abnormalities, that was $92 \%$ in CD and $39 \%$ in UC. Tzakanis et al. [41] investigated the function of small airways using the density dependence of airflow technique in 30 patients with IBD (18 UC and $12 \mathrm{CD}$ ) and 16 healthy subjects. They found that both groups of patients with IBD had an increased volume of isoflow (Viso $\dot{V}$ ) despite their normal baseline spirometric values. The average Viso $\dot{V}$ was lower in active vs. inactive $U C(p<0.05)$, while there was no difference between the two forms of IBD. The mean value of Viso $\dot{V}$ in untreated patients was significantly greater than in control subjects $(p<0.05)$.

"Bronchiolitis" is the most commonly reported disease involving the small airways in patients with $\mathrm{IBD}$, and it is frequently associated with peribronchiolar granuloma [36,42-46]. Camus et al. [35] reported two cases diagnosed with this pathological manifestation among 33 patients. They were young men affected by $U C$, in an inactive phase in one case, who complained of productive cough, and showed diffuse small opacities at chest $\mathrm{x}$-ray and an obstructive pattern at PFT. In this patient the open lung biopsy revealed fibrosing and stenosing bronchiolitis and inflammatory lesions. Both Vandenplas et al. [43] and Trow et al. [47] reported one case each of granulomatous bronchiolitis in women with $\mathrm{CD}$ who had undergone bowel resection. The respiratory alteration presented with nonproductive cough and progressive dyspnea, and chest pain was also reported by Vandenplas' patient. In both cases the CT of the chest demonstrated irregularly dispersed micronodular densities, and the lung biopsy revealed an infiltrate of mononuclear cells associated with non-necrotizing epithelioid granulomas and giant cells in the bronchiolar walls. A $\mathrm{CD} 4^{+}: \mathrm{CD}^{+}$cell ratio of 3:1 in BAL was found in the first patient, whereas in the second patient there was a peribronchial lymphocytic infiltrate and poorly organized granuloma with a normal BAL $\mathrm{CD} 4^{+}: \mathrm{CD}^{+}$ratio.

Sometimes patients complaining of symptoms due to bronchiolitis may erroneously be thought to be affected with asthma, as reported by Bentur et al. [48] in a 13-year-old girl with CD since 8 years of age. The repeated episodes of shortness of breath, which started at age 9 years in this patient, had been interpreted as asthma. CT scan of the chest revealed irregularly diffused ground glass, and lung biopsy showed bronchiolitis obliterans and mononuclear inflammation with noncaseating granulomas, not related to sulfasalazine, because the pulmonary status did not improve when sulfasalazine was stopped.

Also the incidence of "asthma" is far more frequent than previously considered and the disease has a more severe course in IBD patients. A prevalence of $7.1-7.8 \%$ is reported by Bernstein et al. [49], with a higher percentage in women [19].

The airway inflammation sometimes may not be detectable by routine PFT and only an asymptomatic increase in bronchial hyperresponsiveness (BHR) [50] together with high IgE levels may be found during the chronic bowel inflammation despite the absence of atopic symptoms [51,52]. Mansi et al. [53] studied 14 CD children without extraintestinal manifestations, 5 of whom in a phase of clinical remission, with the aim to evaluate the bronchial responsiveness to methacholine in comparison with 10 healthy nonatopic subjects and 10 with mild bronchial asthma. In patients with $C D$, BHR was present in a very high proportion $(71 \%$ of cases) even in the absence of clinical and functional evidence of airways disease. The dose of bronchoconstrictor agent causing a $20 \%$ reduction of FEV 1 compared to baseline $\left(\mathrm{PD}_{20}\right)$ was not related either to the baseline $\mathrm{FEV}_{1}$ or to total blood eosinophil count or serum IgE levels; however the $\mathrm{PD}_{20}$ values found in these patients were higher than those seen in asthmatic individuals. BHR was evident both in atopic patients with CD and in 7 of the 10 nonatopic $C D$ subjects. The higher prevalence of BHR reported in this study than in others [50] may likely depend on the different mean age of the study group and this accords with the observation that BHR progressively decreases with age [54]. BHR was found in several studies with an incidence ranging from 17 to $45 \%$ [50,55]. In a study comparing 30 IBD patients with 16 controls without gastrointestinal disease the respiratory and allergic symptoms were more prevalent in IBD patients $(p<0.04$ and $p<0.007$ respectively) than in the controls, and particularly in UC patients $(p<0.004)$. Abnormal PFTs were present in $27 \%$ of patients $(p<0.04$ vs. controls) and BHR in $17 \%$. Skin prick tests were positive in $50 \%$ IBD but no difference was found between the two IBD subgroups. In 4 of the patients the $\mathrm{PD}_{20}$ value of methacholine $(\mathrm{MCh})$ test was $<16 \mathrm{mg} / \mathrm{ml}$, while negative in all control subjects, and this hyperreactivity index was unrelated to the activity of the intestinal disease [55]. Bartholo et al. [56] found a greater $(p=0.026)$ positivity with methacholine challenge in 15 patients with $\mathrm{CD}$ than in 20 healthy controls, and a higher $(p=0.011)$ level of lymphocytes in induced sputum. These results strengthen the possibility that a subclinical inflammation in absence of pulmonary symptoms can occur. Ceyan et al. [55] demonstrated a higher prevalence of positive skin-prick tests $(p<0.02)$ and increased allergic symptoms $(p<0.007)$ among 30 patients with IBD (19 UC and $11 \mathrm{CD})$ compared to 16 controls without gastrointestinal disease.

Alterations affecting the "lung parenchyma" are relatively rare in IBD patients, and cryptogenic organizing pneumonia (COP) is the most common reported manifestation [35].

\section{Pathogenesis of respiratory complications in IBD}

The current pathogenetic hypothesis of IBD is an impairment of the mucosal immune regulation of the gastrointestinal system concerning intraluminal bacterial antigens in genetically predisposed persons [57]. As a matter of fact, antibodies against intestinal bacteria are frequently detected in serum of patients with IBD (2), and increased titers of anti- 
Saccharomyces cerevisiae antibodies to baker's yeast have been seen in CD patients [58]. One hypothesis to explain the respiratory involvement in IBD is that these products cross-react with common antigens outside the bowel in the human body. Furthermore, a common embryologic origin of both gastrointestinal and bronchial tree may support the onset of inflammation at two different sites with common embryological origin. Respiratory symptoms may also be due to an aberrant homing of inflammatory cells to the lungs from the primary site of chronic inflammation [59], and this might also explain why the large airways disease is frequently not cured by colectomy [38]. Thus, according to this hypothesis, the inflammatory process would shift from the gastrointestinal tract to the airways [60].

A recent study has shown that patients with $C D$ have increased pulmonary permeability which appears unrelated to the disease activity [61]. The same conclusions were reached by Gursoy et al. [62] in their study on UC patients without respiratory symptoms, who underwent technetium-99m aerosol scintigraphy. The increase in permeability might even provide a satisfactory explanation for the occurrence of bronchial hyperresponsiveness (BHR) [53].

It should also be taken into account that not rarely the side effects of treatments may be a cause of pulmonary disease in IBD patients [63], in the form of hypersensitivity reactions and pulmonary edema [64-66]. Usually, most reactions related to sulfasalazine and 5-ASA are seen between 2 and 6 months after commencement of drug administration [19]. Also a relapse or onset of pulmonary tuberculosis may be caused by the immunosuppressant monoclonal antibodies and other anti-inflammatory drugs used to control the chronic intestinal inflammatory process [67-69].

Clinical manifestations and treatment of RD in IBD The involvement of the airways in the course of IBD may manifest itself with persistent productive cough, exertional dyspnea, obstructive and/or restrictive ventilatory deficit with or without abnormal chest radiograph. Interestingly, a severe tracheobronchial stenosis has been reported [70] in a young patient with $\mathrm{CD}$. His respiratory symptoms developed two years after colectomy, with a productive cough initially controlled by beclomethasone. However, ten years later there was an increase in the volume of sputum with purulent features and fever, and a CT scan of the chest showed a marked distortion of the large bronchi with mucoid impaction in the small bronchi and alveolar micronodules. Fiberoptic bronchoscopy (FOB) revealed mucosal inflammation, purulent secretions and tracheal and bronchial deformities, with a severe stenosis of both mainstem bronchi, and marked airflow obstruction at the PFT. The patient was initially treated with antibiotics and oral steroids, tapered over a period of 13 months. After 12 months CT and FOB appeared unchanged, but no mucosal inflammation was present, and symptoms had disappeared at six weeks following the start of therapy; an improvement on PFT was measured at 28 months of switch therapy with inhaled budesonide. This case probably represents an advanced stage of tracheo-bronchial involvement which had developed over a long period of time.

Symptoms due to bronchiectasis and chronic bronchitis are the most frequent clinical presentation of airways pathology in IBD, generally following the onset of bowel disease and sometimes after the colectomy (71). Also in the series reported by Kelly et al. [39], $80 \%$ of IBD patients with bronchiectasis developed their symptoms after surgery for IBD, supporting Kinnear's and Higenbottam's hypothesis that inflammatory process may shift from the bowel to the airway [60] and manifest or increase after the bowel inflammation has been eliminated [39]. In a series collected by Higenbottam et al. [72], ten patients with $\mathrm{UC}$, all non smokers, presented productive cough. Six out of these had normal chest radiograph and three a minor obstructive ventilatory defect on PFT. In one of these patients bronchography revealed the presence of bronchiectasis. The remaining 4 patients developed a marked exertional dyspnea and bilateral pulmonary shadows on the chest X-ray with a mixed ventilatory defect. There was no correlation with sulfasalazine therapy and in 3 patients the symptoms began after colectomy. In 7 patients the symptoms were relieved by inhaled beclomethasone.

However the presence of respiratory symptoms may be highly variable in IBD patients and completely absent in those with milder disease. In fact, HRCT performed in 17 IBD patients (3 out of 17 were CD patients) revealed bronchiectasis in $13(76 \%)$, in the absence of sputum production in those with a lesser extent of bronchial alteration, while 9 patients presented signs of air trapping, and 5 a "tree in bud" pattern at CT [73].

As regards asthma symptoms, Bernstein et al. [74] report an increased risk for this disease in either form of IBD in a population-based study screening for a number of other chronic inflammations. Asthma was the second most common extraintestinal comorbidity, after arthritis, without significant differences in relation to the type of IBD and gender, although a slightly greater prevalence in women was present [19].

Sometimes patients complain of dyspnea on exertion or even at rest, nonproductive cough, fever and general malaise due to the involvement of lung parenchyma in the form of interstitial and alveolar diffuse changes. In these cases it is necessary to distinguish the alterations directly consequent to the bowel disease from those caused by adverse reactions to the drugs used for IBD. Alterations of the lung parenchyma are more frequent in $\mathrm{UC}$ and in females, cryptogenic organizing pneumonia (COP) being the most reported single case [36]. In most patients $[21,35,75-78]$ COP generally follows the onset of IBD, and it presents with fever, dyspnea, dry cough, pleuritic chest pain and weight loss. 
Areas of peribronchiolar inflammation and fibrosis and/or fibrosis of the peribronchial region [24] or subpleural opacities [78] have been seen on CT scan, with a tendency to migrate and consolidate [77]. At physical examination of the chest, inspiratory crackles are found on both sides of the chest, and pulmonary function tests show a restrictive pattern. The culture of bronchoalveolar lavage fluid generally does not lead to the growth of bacteria, acid-fast bacilli or fungi, and the cytologic study shows an increased percentage of lymphocytes with a variable, although usually normal, CD4/CD8 ratio. A normal CD4/CD8 ratio is reported by Simon [77], whereas Carratù [78] found it increased. In this case an open-lung biopsy revealed isolated foci of non-specific chronic inflammation, myofibroblastic proliferation and peripheral endoalveolar foamy macrophages. Rarely, cases of pulmonary infiltrates and eosinophilia have been reported both before and during or after the diagnosis of IBD [35]. Dry cough was the only symptom referred by a 38year-old woman affected by $C D$ and treated with mesalazine [79]. Chest x-ray showed some alveolar opacities in the right middle lobe, that were interpreted as pneumonitis and successfully treated with antimicrobial drugs. However the pulmonary infiltrates relapsed despite the intense antibiotic therapy previously adopted. BAL was performed and the cellular examination revealed a marked increase $(30 \%)$ in eosinophilis. At surgical biopsy a pattern of interstitial fibrosis with few non-caseating epithelioid granulomas was demonstrated, together with sparse lesions of bronchiolitis obliterans and desquamative interstitial pneumonia. This was the first description of a necrobiotic pulmonary nodule associated with interstitial pneumonia and eosinophilia. However, the hypothesis - albeit unlikely - that mesalazine treatment was responsible was difficult to confirm or exclude because, while the first pneumonia resolved without the withdrawl of the drug, the relapse improved after corticosteroid therapy and discontinuation of treatment with 5-ASA.

As to the pulmonary complications derived from the use of drugs for IBD, sulfasalazine was first prescribed in the management of these chronic bowel diseases in the 1940s [80]. It is a compound of sulfapyridine linked to 5-ASA (mesalazine) [19]. It is known that the drug may have clinically important side-effects, including pulmonary toxicity [80]. In this respect, a retrospective study on published reports between 1972 and 1999 [80] revealed that lung toxicity caused by sulfasalazine is more common in ulcerative colitis, where it mainly manifests with dyspnea ( $80 \%$ of cases), fever $(70 \%)$ and cough $(64 \%)$. Peripheral eosinophilia was reported in $52 \%$ of cases. Interestingly, the respiratory function assessment showed abnormalities in 28 out of 29 tests performed, consisting in a restrictive defect in $66 \%$ of cases. Chest radiography was abnormal in all cases, showing mainly pulmonary infiltrates, that were confirmed at CT scan, where it revealed typical infiltrates, ground glass opacities, and pul- monary nodules with central cavitation. BAL was performed in 11 patients, with 5 (45.4\%) demonstrating an increase in eosinophils ranging from 23 to $69 \%$. Based on the histological findings, the final diagnosis was eosinophilic pneumonia in 11 cases, and in 4 fibrosing alveolitis. Other less common histological diagnoses included COP, desquamative interstitial pneumonia (DIP) and less specified pneumopathies, like sulfasalazine lung disease or pulmonary hypersensitivity reaction.

Averbuch et al. [81] reported a case of rash urticaria and generalized angioedema in a 58-year-old man suffering from $U C$ and treated with sulfasalazine therapy, where the adverse symptoms resolved with the discontinuation of the drug. The patient underwent a protocol of desensitization (gradually increasing doses of sulfasalazine with progressive tapering of prednisone), and after two months he developed a dry cough, fever and progressive dyspnea. A chest X-ray showed diffuse bilateral interstitial infiltrates which dramatically improved with sulfasalazine discontinuation and administration of high dose prednisone. In this case the first manifestations may be interpreted as a typical allergic reaction, whereas the parenchymal lung alterations likely reflect a direct toxicity of the drug. Alternatively, both features could be due to the same steroidresponsive mechanism, but with higher doses of prednisone necessary for the prevention of the interstitial pneumonia. In a case of eosinophilic pneumonia in a 35-year-old woman treated with oral mesalazine, who improved after discontinuation of therapy, the lymphocyte stimulation test with the drug was positive for mesalazine and negative for sulfasalazine and sulphapyridine [65].

Only few cases $[82,83]$ of pneumonitis have been reported in patients treated with methotrexate for IBD, whereas one series reported 70 cases of tuberculosis in IBD patients given therapy with infliximab (anti-tumor necrosis factor monoclonal antibody) [84].

Inhaled steroids are very effective, also for the long term control of the respiratory disease, in patients with chronic bronchitis, in symptomatic asthmatic patients, and in upper airways disease too [70]. Oral corticosteroids can improve interstitial disease [35], COP [76,78], granulomatous bronchiolitis [43], and drug-induced pneumonia [81], while intravenous administration is the initial management of life-threatening subglottis stenosis or extensive interstitial lung disease [35]. A surgical approach is sometimes necessary to repair the sequels of destructive inflammatory processes, like tracheal and bronchial stenosis.

\section{Causes of mortality in IBD}

Despite the marked improvement in medical and surgical therapy, it remains a debated issue whether the death risk is greater in IBD patients compared to the general population, also because dissimilar results have been reported in many studies, where the most severe patients, bearing the worse prognosis, are prevalently included [85]. Other factors like 
malnutrition, infection, and side effects of medical and surgical therapy may increase the fragility of these patients.

Cucino et al. [86], with the aim to analyze the comorbidities possibly contributing to increased mortality of patients with IBD, pooled the data from 6 consecutive years (1991-1996) and analyzed them together. In patients affected with UC the comorbidities were most frequently represented by shock and protein/calorie malnutrition, volume depletion and anemia, septicemia, and peritonitis, whereas CD patients often showed nutritional, volume and electrolyte disturbances, besides surgical complication and pulmonary insufficiency.

A meta-analysis was carried out to ascertain the overall and cause-specific mortality in a cohort of UC patients published in the literature from 1965 to 2006 [85]. Five Scandinavian studies included in this meta-analysis reported higher mortality rates (SMR 1.2, $\mathrm{p}=0.001$ ) than did non-Scandinavian countries, similarly to an EC-IBD study (European Collaborative group of Inflammatory Bowel Disease) that reported a slightly higher mortality in North Europe than in Southern Europe [87]. The studies which presented SMRs stratified for age at diagnosis did not show significant differences, whereas those which considered the extent of $U C$ at diagnosis showed a higher SMR when the inflammation was close to the rectum (1.2). Similarly, the SMR was higher during the first 5 years after the diagnosis (1.4) and especially during the first year (2.2) (88). Lower SMR (0.8) was encountered in UC patients who had not been given immunosuppressive drugs (6-mercaptopurine, azathioprine or infliximab) and in non-colectomized patients (0.9). The mean percentage of deaths ascribed to $\mathrm{UC}$ was $17 \%$ (ranging from $11 \%$ to $30 \%$ ), the most common causes being colorectal cancer and surgical or postoperative complications. Six out of ten series reported SMRs for specific causes of deaths. A significantly lower risk of dying from lung cancer was observed (SMR 0.3, $\mathrm{p}=0.04$ ), whereas a greater, but not significant, risk of dying from COPD (SMR 1.6, $p=0.26$ ) and a significant risk for pneumonia (SMR 3.1, p > 0.001) were found. Only one study estimated the risk of dying from pulmonary embolism, reporting a significantly higher SMR of 4.0. The lower SMR reported for lung cancer may be due to the fact that UC patients often are non smokers, so that the difference in smoking habits between the UC patients and the healthy population may act as a confounding factor. The other reported causes of death include cardiovascular, renal and liver diseases, leukemia and nonHodgkin's lymphoma.

The EC-IBD study [87] on mortality in UC in Europe did not find a higher mortality risk in UC patients compared with the normal population. The mortality was slightly higher in females than in males (SMR 1.39 and 0.92 respectively) and slightly higher in older patients. A comparison of disease specific mortality between North European region and South European region also revealed a higher SMR only for pulmonary disease (SMR 1.19 and 0,82 respectively).

Similarly, investigating the overall and cause-specific mortality in CD, Duricova et al. [89] examined the results from nine studies, six of which also reported cause-specific mortality. A slightly but significantly increased pooled SMR (1.39) for mortality in general was observed, with no significant gender difference although it was higher in women, whereas a higher significant SMR for mortality due to pulmonary diseases was found in CD compared to the general population and $U C$ patients. In this metaanalysis a significantly increased risk of death from lung cancer was detected (SMR 2.72), as well as from COPD (SMR 2.55), that led to a tendency of risk of overall death from respiratory disease to be increased (SMR 1.44). This can likely be explained by a higher prevalence of smokers among CD patients compared to the general population and to UC patients, and it is known that smoking has detrimental effects on the clinical course of CD [90]. Another meta-analysis by Canavan et al. [91], performed in the same type of patients, revealed higher SMR in hospital and referral centers with respect to community-based studies.

\section{CONCLUSIONS}

In conclusion, the inflammatory process of IBD is not necessarily restricted to the gastrointestinal tract, since many studies have demonstrated that latent or patent pulmonary involvement can occur in these patients even in the complete absence of symptoms [92]. The available diagnostic tools may make us able to detect early IBD-related respiratory syndromes.

A bronchial hyperresponsiveness in patients affected with UC or CD and no respiratory symptoms can easily be detected by methacholine challenge, so indicating that in the airways an inflammation not detectable by routine PFTs may exist [53]. Use of the density dependence of air-flow technique may help to clarify if small airways are affected [41], and a defect in the transfer of respiratory gases, as expressed by the decrease in the $\mathrm{DL}_{\mathrm{CO}}$, suggests the presence of a process involving the interstitial pulmonary district possibly not identifiable by standard chest radiographs [27]. In this context, HRCT scan obtained at full expiration is a valid tool to show air trapping mainly in patients with emphysema [93], asthma [94] and hypersensitivity pneumonia [95] even in the absence of recognizable morphologic abnormalities on inspiratory scans [40]. This method can be useful to detect small airways involvement also in asymptomatic IBD patients.

As previously reported, pulmonary involvement, encountered in about $60 \%$ of IBD patients [96], can range from a simple defect of pulmonary function without symptoms to fibrosing alveolitis with a greater risk of mortality. For this reason the early detection of latent abnormalities of pulmonary function is important to prevent future and more severe respiratory impairment [56]. Early detection is all the more war- 
ranted in view of the fact that IBD-related respiratory syndromes generally respond well to inhaled or systemic corticosteroid treatment $[25,35,70]$.

\section{References}

1. Turner JR. Molecular basis of epithelial barrier regulation: from basic mechanisms to clinical application. Am J Pathol 2006;169:1901-1909.

2. Bamias G, Nyce M, De La Rue S, Cominelli F; American College of Physicians; American Physiological Society. New concepts in the pathophysiology of inflammatory bowel disease. Ann Intern Med 2005;143:895-904.

3. Lodes M, Cong Y, Elson CO, Mohamath R, Landers CJ, Targan SR, Fort M, Hershberg RM. Bacterial flagellin is a dominant antigen in Crohn disease. J Clin Invest 2004;113:1296-1306.

4. Barnich N, Carvalho FA, Glasser AL, Darcha C, Jantscheff $P$, Allez $M$, Peeters $H$, Bommelaer G, Desreumaux $P$, Colombel JF, Darfeuille-Michaud A. CEACAM6 acts as a receptor for adherent-invasive $E$. coli, supporting ileal mucosa colonization in Crohn disease. J Clin Invest 2007; 117:1566-1574.

5. Abraham C, Cho JH. Inflammatory bowel disease. N Engl J Med 2009;19:2066-2078.

6. Fuss IJ, Neurath $M$, Boirivant $M$, Klein JS, de la Motte C, Strong SA, Fiocchi C, Strober W. Disparate CD4+ lamina propria (LP) lymphokine secretion profiles in inflammatory bowel disease. Crohn's disease LP cells manifest increased secretion of INF-gamma, whereas ulcerative colitis LP cells manifest increased secretion of IL-5. J Immunol 1996;157:1261-1270.

7. Fujino S, Andoh A, Bamba S, Ogawa A, Hata K, Araki Y, Bamba T, Fujiyama Y. Increased expression of interleukin 17 in inflammatory bowel disease. Gut 2003;52:65-70.

8. Hugot JP, Laurent-Puig P, Gower-Rousseau C, Olson JM, Lee JC, Beaugerie L, Naom I, Dupas JL, Van Gossum A, Orholm M, Bonaiti-Pellie C, Weissenbach J, Mathew CG, LennardJones JE, Cortot A, Colombel JF, Thomas G. Mapping of a susceptibility locus for Crohn's disease on chromosome 16. Nature 1996;379:821-823.

9. Cavanaugh J; IBD International Genetics Consortium. International collaboration provides convincing linkage replication in complex disease through analysis of a large pooled data set: Crohn disease and chromosome 16. Am J Hum Genet 2001;68:1165-1171.

10. Abraham C, Cho JH. Functional consequences of NOD2 (CARD15) mutations. Inflamm Bowel Dis 2006;12:641650.

11. Kobayashi KS, Chamaillard M, Ogura $\mathrm{Y}$, Henegariu $\mathrm{O}$, Inohara N, Nuñez G, Flavell RA. Nod2-dependent regulation of innate and adaptive immunity in the intestinal tract. Science 2005;307:731-734.

12. Lesage S, Zouali H, Cézard JP, Colombel JF, Belaiche J, Almer S, Tysk C, O'Morain C, Gassull M, Binder V, Finkel Y, Modigliani R, Gower-Rousseau C, Macry J, Merlin F, Chamaillard M, Jannot AS, Thomas G, Hugot JP; EPWG-IBD Group; EPIMAD Group; GETAID Group. CARD15/NOD2 mutational analysis and genotype-phenotype correlation in 612 patients with inflammatory bowel disease. Am J Hum Genet 2002;70:845-857.

13. Economou M, Trikalinos TA, Loizou KT, Tsianos EV, loannidis JP. Differential effects of NOD2 variants on Crohn's disease risk and phenotype in diverse populations: a metaanalysis. Am J Gastroenterol 2004;99:2393-2404.

14. Hampe J, Franke A, Rosenstiel P, Till A, Teuber M, Huse K, Albrecht M, Mayr G, De La Vega FM, Briggs J, Günther S,
CONFLICT OF INTEREST STATEMENT: None of the authors has any conflict of interest to declare in relation to the subject of this manuscript.

Prescott NJ, Onnie CM, Häsler R, Sipos B, Fölsch UR, Lengauer T, Platzer M, Mathew CG, Krawczak M, Schreiber $\mathrm{S}$. A genome-wide association scan of nonsynonymous SNPs identifies a susceptibility variant for Crohn disease in ATG16L1. Nat Genet 2007;39:207-211.

15. Cadwell K, Liu JY, Brown SL, Miyoshi H, Loh J, Lennerz JK, Kishi C, Kc W, Carrero JA, Hunt S, Stone CD, Brunt EM, Xavier RJ, Sleckman BP, Li E, Mizushima N, Stappenbeck TS, Virgin HW 4th. A key role for autophagy and the autophagy gene Atg16l1 in mouse and human intestinal Paneth cells. Nature 2008;456:259-263.

16. Levine B, Deretic V. Unveiling the roles of autophagy in innate and adaptive immunity. Nat Rev Immunol 2007;7:767-777.

17. Nedjic J, Aichinger M, Emmerich J, Mizushima N, Klein L. Autophagy in thymic epithelium shapes the T-cell repertoire and is essential for tolerance. Nature 2008;455:396-400.

18. Kraft SC, Earle RH, Roesler M, Esterly JR. Unexplained bronchopulmonary disease with inflammatory bowel disease. Arch Intern Med 1976;136:454-459.

19. Storch I, Sachar D, Katz S. Pulmonary manifestations of inflammatory bowel disease. Inflamm Bowel Dis 2003;9:104-115.

20. Greenstein AJ, Janowitz HD, Sachar DB. The extra-intestinal complications of Crohn's disease and ulcerative colitis: a study of 700 patients. Medicine 1976;55:401-412.

21. Veloso FT, Carvalho J, Magro F. Immune-related manifestations of inflammatory bowel disease. A prospective study of 792 patients. J Clin Gastroenterol 1996;23:29-34.

22. Edwards FC, Truelove SC. The course and prognosis of ulcerative colitis. III. Complications. Gut 1964;5:1-22.

23. Rogers BH, Clark LM, Kirsner JB. The epidemiologic and demographic characteristics of inflammatory bowel disease: an analysis of a computerized file of 1400 patients. J Chronic Dis 1971; 24:743-773.

24. Raj AA, Birring SS, Green R, Grant A, de Caestecker J, Pavord ID. Prevalence of inflammatory bowel disease in patients with airways disease. Respir Med 2008;102:780785.

25. Camus P, Colby TV. The lung in inflammatory bowel disease. Eur Respir J 2000;15:5-10.

26. Mohamed-Hussein AA, Mohamed NA, Ibrahim ME. Changes in pulmonary function in patients with ulcerative colitis. Respir Med 2007;101:977-982.

27. Munck A, Murciano D, Pariente R, Cezard JP, Navarro J. Latent pulmonary function abnormalities in children with Crohn's disease. Eur Respir J 1995;8:377-380.

28. Tzanakis N, Bouros D, Samiou M, Panagou P, Mouzas J, Manousos $\mathrm{O}$, Siafakas N. Lung function in patients with inflammatory bowel disease. Respir Med 1998;92:516-522.

29. Herrlinger KR, Noftz MK, Dalhoff K, Ludwig D, Stange EF, Fellermann K. Alterations in pulmonary function in inflammatory bowel disease are frequent and persist during remission. Am J Gastroenterol 2002;97:377-381.

30. Douglas JG, McDonald CF, Leslie MJ, Gillon J, Crompton GK, McHardy GJ. Respiratory impairment in inflammatory bowel disease: does it vary with disease activity? Respir Med 1989;83:389-394.

31. Bonniere $P$, Wallaert $B$, Cortot $A$, Marchandise $X$, Riou $Y$, Tonnel AB, Colombel JF, Voisin C, Paris JC. Latent pulmonary involvement in Crohn's disease: biological, func- 
tional, bronchoalveolar lavage and scintigraphic studies. Gut 1986;27:919-925.

32. Dierkes-Globisch A, Mohr H. Pulmonary function abnormalities in respiratory asymptomatic patients with inflammatory bowel disease. Eur J Intern Med 2002;13:385.

33. Wallaert B, Colombel JF, Tonnel AB, Bonniere P, Cortot A, Paris JC, Voisin C. Evidence of lymphocyte alveolitis in Crohn's disease. Chest 1985;87:363-367.

34. Sarioğlu N, Türkel N, Sakar A, Celik P, Saruç M, Demir MA, Göktan C, Kirmaz C, Yüceyar H, Yorgancioğlu A. Lung involvement in inflammatory bowel diseases. Ann Saudi Med 2006;26:407-408.

35. Camus P, Piard F, Ashcroft T, Gal AA, Colby TV. The lung in inflammatory bowel disease. Medicine 1993;72:151-183.

36. Black H, Mendoza M, Murin S. Thoracic manifestations of inflammatory bowel disease. Chest 2007;131:524-532.

37. Fishman AP, Fishman JA, Grippi MA, Elias JA, Senior RM, Pack AI. In: Fishman AP, ed. Fishman's pulmonary diseases and disorders. New York: McGraw Hill, 1998:838.

38. Spira A, Grossman R, Balter M. Large airway disease associated with inflammatory bowel disease. Chest 1998;113:1723-1726.

39. Kelly MG, Frizelle FA, Thornley PT, Beckert L, Epton M, Lynch AC. Inflammatory bowel disease and the lung: is there a link between surgery and bronchiectasis? Int J Colorectal Dis 2006;21:754-757.

40. Songür $N$, Songür $Y$, Tüzün $M$, Doğan I, Tüzün $D$, Ensari $A$, Hekimoglu B. Pulmonary function tests and high-resolution $\mathrm{CT}$ in the detection of pulmonary involvement in inflammatory bowel disease. J Clin Gastoenterol 2003;37:292-298.

41. Tzanakis N, Samiou M, Bouros D, Mouzas J, Kouroumalis E, Siafakas NM. Small airways function in patients with inflammatory bowel disease. Am J Respir Crit Care Med 1998;157:382-386

42. Kraft SC, Earle RH, Roesler M, Esterly JR. Unexplained bronchopulmonary disease with inflammatory bowel disease. Arch Intern Med 1976;136:454-459.

43. Vandenplas O, Casel S, Delos M, Trigaux JP, Melange M, Marchand E. Granulomatous bronchiolitis associated with Crohn's disease. Am J Respir Crit Care Med 1998;158:1676-1679.

44. Desai SJ, Gephardt GN, Stoller JK. Diffuse panbronchiolitis preceding ulcerative colitis. Chest 1989;95:1342-1344.

45. Hilling GA, Robertson DA, Chalmers AH, Rigby HS. Unusual pulmonary complication of ulcerative colitis with a rapid response to corticosteroids: case report. Gut 1994;35:847-848.

46. Ward H, Fisher KL, Waghray R, Wright JL, Card SE, Cockcroft DW. Constrictive bronchiolitis and ulcerative colitis. Can Respir J 1999;6:197-200.

47. Trow TK, Morris DG, Miller CR, Homer RJ. Granulomatous bronchiolitis of Crohn's disease successfully treated with inhaled budesonide. Thorax 2009;64:546-547.

48. Bentur L, Lachter J, Koren I, Ben-Izhak O, Lavy A, Bentur Y, Rosenthal E. Severe pulmonary disease in association with Crohn's disease in a 13-year-old girl. Pediatr Pulmonol 2000;29:151-154.

49. Bernstein CN, Blanchard JF, Rawsthorne P, Yu N. The prevalence of extraintestinal diseases in inflammatory bowel disease: a population-based study. Am J Gastroenterol 2001;96:1116-1122.

50. Louis E, Louis R, Drion V, Bonnet V, Lamproye A, Radermecker $M$, Belaiche J. Increased frequency of bronchial hyperresponsiveness in patients with inflammatory bowel disease. Allergy 1995;50:729-733.

51. Troncone R, Merrett TG, Ferguson A. Prevalence of atopy is unrelated to presence of inflammatory bowel disease. Clin Allergy 1988;18:111-117.

52. Levo $Y$, Shalit $M$, Wollner S, Fich A. Serum IgE levels in patients with inflammatory bowel disease. Ann Allergy 1986;56:85-87.

53. Mansi A, Cucchiara S, Greco L, Sarnelli P, Pisanti C, Franco MT, Santamaria F. Bronchial hyperresponsiveness in children and adolescents with Crohn's disease. Am J Respir Crit Care Med 2000;161:1051-1054.

54. Clifford RD, Radford M, Howell JB, Holgate ST. Prevalence of respiratory symptoms among 7 and 11 year old schoolchildren and association with asthma. Arch Dis Child 1989:64:1118-1125.

55. Ceyhan BB, Karakurt S, Cevik H, Sungur M. Bronchial hyperreactivity and allergic status in inflammatory bowel disease. Respiration 2003;70:60-66.

56. Bartholo RM, Zaltman C, Elia C, Cardoso AP, Flores V, Lago P, Cassabian L, Dorileo FC, Lapa-e-Silva JR. Bronchial hyperresponsiveness and analysis of induced sputum cells in Crohn's disease. Braz J Med Biol Res 2005;38:197-203.

57. Bouma G, Strober W. The immunological and genetic basis of inflammatory bowel disease. Nat Rev Immunol 2003;3:521-533.

58. Main J, McKenzie H, Yeaman GR, Kerr MA, Robson D, Pennington CR, Parratt D. Antibody to Saccharomyces cerevisiae (bakers' yeast) in Crohn's disease. BMJ 1988;297:1105-1106.

59. Birring SS, Birghtling CE, Symon FA, Barlow SG, Wardlaw AJ, Pavord ID. Idiopathic chronic cough: association with organ specific autoimmune disease and bronchoalveolar lymphocytosis. Thorax 2003;58:1066-1070.

60. Kinnear W, Higenbottam T. Pulmonary manifestations of inflammatory bowel disease. Intern Med Spec 1983;4:104111.

61. Adenis A, Colombel JF, Lecouffe P, Wallaert B, Hecquet B, Marchandise X, Cortot A. Increased pulmonary and intestinal permeability in Crohn's disease. Gut 1992;33:678-682.

62. Gursoy S, Guven K, Kula M, Canoz O, Yurci A, Unluhizarci K, Ozbakir O, Yucesoy M. Subclinical alveolar involvement in ulcerative colitis. Inflamm Bowel Dis 2005;11:372- 375.

63. Ludwig D, Stange EF. Treatment of ulcerative colitis. Hepatogastroenterology 2000;47:83-89.

64. Ford RM. Transient pulmonary eosinophilia and asthma. A review of 20 cases occurring in 5,702 asthma sufferers. Am Rev Respir Dis 1966;93:797-803.

65. Tanigawa K, Sugiyama K, Matsuyama H, Nakao H, Kohno K, Komuro Y, Iwanaga Y, Eguchi K, Kitaichi M, Takagi H. Mesalazine-induced eosinophilic pneumonia. Respiration 1999;66:69-72.

66. Heffner JE, Sahn S. Salycilate-induced pulmonary edema. Clinical features and prognosis. Ann Intern Med 1981;95:405-409.

67. Serghini M, Karoui S, Meknini M, Matri S, Kallel L, Fekih M, Boubaker J, Filali A. Treatment of Crohn's disease by infliximab. About 20 cases. Tunis Med 2009;87:579-582.

68. Takasaka N, Toyota E, Shimada M, Ariga H, Teramoto S, Akagawa S. Two cases of tuberculosis after treatment of rheumatoid arthritis with infliximab. Nihon Kokyuki Gakkai Zasshi 2010;48:60-65.

69. Dixon WG, Hyrich KL, Watson KD, Lunt M, Galloway J, Ustianowski A; B S R B R Control Centre Consortium, Symmons DP; BSR Biologics Register. Drug-specific risk of tuberculosis in patients with rheumatoid arthritis treated with anti-TNF therapy: results from the British Society for Rheumatology Biologics Register (BSRBR). Ann Rheum Dis 2010;69:522-528.

70. Kuźniar T, Sieiman C, Brugière O, Groussard O, Mal H, Mellot F, Pariente R, Malolepszy J, Fournier M. Severe tracheobronchial stenosis in a patient with Crohn's disease. Eur Respir J 2000;15:209-212.

71. Eaton TE, Lambie N, Wells AJ. Bronchiectasis following colectomy for Crohn's disease. Thorax 1998;53:529- 531. 
72. Higenbottam T, Cochrane GM, Clark TJ, Turner D, Millis R, Seymour W. Bronchial disease in ulcerative colitis. Thorax 1980;35:581-585.

73. Mahadeva R, Walsh G, Flower CD, Shneerson JM. Clinical and radiological characteristics of lung disease in inflammatory bowel disease. Eur Respir J 2000;15:41-48.

74. Bernstein CN, Wajda A, Blanchard JF. The clustering of other chronic inflammatory diseases in inflammatory bowel disease: a population-based study. Gastroenterology 2005;129:827-836.

75. Mahajan L, Kay M, Wyllie R, Steffen R, Goldfarb J. Ulcerative colitis presenting with bronchiolitis obliterans organizing pneumonia in a pediatric patient. Am J Gastroenterol 1997;92:2123-2124.

76. Swinburn CR, Jackson GJ, Cobden I, Ashcroft T, Morritt GN, Corris PA. Bronchiolitis obliterans organising pneumonia in a patients with ulcerative colitis. Thorax 1988;43:735-736.

77. Gil-Simón P, Barrio Andrés J, Atienza Sánchez R, Julián Gómez L, López Represa C, Caro-Patón A. Bronchiolitis obliterans organizing pneumonia and Crohn's disease. Rev Esp Enferm Dig 2008;100:175-177.

78. Carratù P, Dragonieri S, Nocerino MC, Trabucco SM, Lacedonia D, Parisi G, Resta O. A case of cryptogenic organizing pneumonia occurring in Crohn's disease. Can Respir J 2005;12:437-439.

79. Faller M, Gasser B, Massard G, Pauli G, Quoix E. Pulmonary migratory infiltrates and pachypleuritis in a patient with Crohn's disease. Respiration 2000;67:459-463.

80. Parry SD, Barbatzas C, Peel ET, Barton JR. Sulfasalazine and lung toxicity. Eur Respir J 2002;19:756-764.

81. Averbuch M, Halpern Z, Hallak A, Topilsky M, Levo Y. Sulfasalazine pneumonitis. Am J Gastroenterol 1985;80:343-345.

82. Margagnoni G, Papi V, Aratari A, Triolo L, Papi C. Methotrexate-induced pneumonitis in a patients with Crohn's disease. Journal of Crohn's and Colitis 2010;4:211214.

83. Brechmann T, Heyer C, Schmiegel W. Methotrexateinduced pneumonitis in a woman with Crohn's disease. Dtsch Med Wochenschr 2007;132:1759-1762.

84. Keane J, Gershon S, Wise RP, Mirabile-Levens E, Kasznica J, Schwieterman WD, Siegel JN, Braun MM. Tuberculosis associated with infliximab, a tumor necrosis factor alphaneutralizing agent. N Engl J Med 2001;345:1098-1104.

85. Jess T, Gamborg M, Munkholm P, Sørensen TI. Overall and cause-specific mortality in ulcerative colitis: meta-analysis of population-based inception cohort studies. Am J Gastroenterol 2007;102:609-617.

86. Cucino C, Sonnenberg A. Cause of death in patients with inflammatory bowel disease. Inflamm Bowel Dis 2001;7:250-255.

87. Höie O, Schouten LJ, Wolters FL, Solberg IC, Riis L, Mouzas IA, Politi P, Odes S, Langholz E, Vatn M, Stockbrügger RW, Moum B; European Collaborative Study Group of Inflammatory Bowel Disease (EC-IBD). Ulcerative colitis: no rise in mortality in a European-wide population based cohort 10 years after diagnosis. Gut 2007; 56:497-503.

88. Jacobsen B, Puho E, Fallingborg J, et al. Mortality in ulcerative colitis in the North Jutland County. A population based 26 years follow-up study. (Abstr). Gut 2005;54:A6.

89. Duricova D, Pedersen N, Elkjaer $M$, Gamborg $M$, Munkholm P, Jess T. Overall and cause-specific mortality in Crohn's disease: a meta-analysis of population-based studies. Inflamm Bowel Dis 2010;16:347-353.

90. Birrenbach T, Böcker U. Inflammatory bowel disease and smoking: a review of epidemiology, pathophysiology, and therapeutic implications. Inflamm Bowel Dis 2004;10:848859.

91. Canavan C, Abrams K, Mayberry JF. Meta-analysis: mortality in Crohn's disease. Aliment Pharmacol Ther 2007;25:861870.

92. Karadag F, Ozhan MH, Akçiçek E, Günel O, Alper H, Veral A. Is it possible to detect ulcerative colitis-related respiratory syndrome early? Respirology 2001;6:341-346.

93. Gevenois PA, De Vuyst P, Sy M, Scillia P, Chaminade L, de Maertelaer V, Zanen J, Yernault JC. Pulmonary emphysema: quantitative CT during expiration. Radiology 1996;199:825-829.

94. Newman KB, Lynch DA, Newman LS, Ellegood D, Newell JD Jr. Quantitative computed tomography detects air trapping due to asthma. Chest 1994;106:105-109.

95. Hansell DM, Wells AU, Padley SP, Müller NL. Hypersensitivity pneumonitis: correlation of individual CT patterns with functional abnormalities. Radiology 1996;199:123-128.

96. Kuzela L, Vavrecka A, Prikazska M, Drugda B, Hronec J, Senkova A, Drugdova M, Oltman M, Novotna T, Brezina M, Kratky A, Kristufek P. Pulmonary complications in patients with inflammatory bowel disease. Hepatogastroenterology 1999;46:1714-1719. 